\title{
A POPUlARIZAÇÃO NA CIÊNCIA: A ÓPTICA DE NEWTON NO SÉCULO XVIII
}

\author{
Boniek Venceslau da Cruz Silva \\ Pós-graduação em Ensino de Ciências Naturais e Matemática/ Esc. Est. Presidente \\ Roosevelt. E-mail: boniekvenc@yahoo.com.br
}

\begin{abstract}
RESUMO
As atuais aulas de ciências, geralmente, não apresentam discussões referentes à aspectos da natureza da ciência, por exemplo, como uma teoria se desenvolve com o tempo e a influência de fatores não-racionais na sua construção. Tais aspectos são relevantes na hora do aluno desenvolver uma visão mais adequada na sua compreensão de como uma teoria ou modelo é construído. Além disso, as abordagens mais tradicionais, também, já não garantem a aprendizagem de teorias físicas. Com a inserção de discussões, que envolvam a História e a Filosofia da Ciência (HFC), os alunos poderão vivenciar o desenvolvimentos de teorias físicas e, também, realizar estudos sobre a natureza da ciência, colocando em evidência aspectos não abordados nas práticas mais tradiconais. Este estudo é baseado em uma pesquisa bibliográfica, que contempla a história da óptica, e, em especial, a controvérsia existente em relação a natureza da luz com destaque a influência newtoniana para a aceitação da teoria corpuscular no século XVIII. Neste trabalho problematizaremos uma visão ingênua do desenvolvimento histórico da ciência, onde, geralmente, ela é vista de forma contínua e fatores não-racionais são excluídos da construção de teorias físicas.
\end{abstract}

PALAVRAS-CHAVE: história e filosofia da ciência, popularização na ciência, Isaac Newton.

\section{THE POPULARIZATION IN SCIENCE: THE NEWTON APPROACH IN THE EIGHTEENTH CENTURY}

\begin{abstract}
The current science classes generally do not have discussions concerning aspects of the nature of science, for example, as a theory developed over time, the influence of nonrational factors in its construction. These aspects are relevant at the time of the student developing a more appropriate method in their understanding of how a theory or model is built. In addition to more traditional approaches, too, no longer guaranteeing the physical theories of learning. With the insertion of discussions, involving the History and Philosophy of Science, students can experience the development of physical theories, and also carry out research into the nature of science, bringing to light issues not addressed in more traditional practices. This study is based on a literature search, which covers the history of optics, and in particular the existing controversy regarding the nature of light to highlight the Newtonian influence for the acceptance of the corpuscular theory in the eighteenth century. In this work problems were a naive view of the historical development of science, where, usually, it is seen as continuous and non-rational factors are excluded from the construction of physical theories.
\end{abstract}

KEYWORDS: history and philosophy of science, science popularization, Isaac Newton. 


\section{A POPUlARIZAÇÃo NA CIÊNCIA: A ÓPTICA DE NEWTON NO SÉCULO XVIII}

\section{INTRODUÇÃO}

Nos dias atuais, as tradicionais aulas de Físicas já se mostram incapazes, muitas vezes, de propiciar uma aprendizagem significativa aos estudantes. Conjuntamente a isto a forma tradicional das nossas aulas, em muitos casos, não são capazes de, também, garantir um aprendizado sobre a natureza do seu conhecimento.

A falta de uma abordagem sobre a natureza da ciência ${ }^{1}(\mathrm{NdC})$ atrelado a uma metodologia deficitária ao apresentar teorias científicas ocasionam nos alunos idéias equivocadas em relação a natureza da ciência, bem como muitas dúvidas relacionadas a aspectos básicos de teorias físicas, por exemplo, reflexão e refração.

Hoje, a literatura especializada (MATTHEWS, 1995; VANNUCCHI, 1996; SOLBES; TRAVER, 1996; CAMPANARIO, 1998; BRASIL, 2002; MARTINS, 2007; SILVA; MARTINS,2008) reconhece a influência da história e da filosofia da ciência (HFC) ao ensino de ciência, e, em particular, o de Física.

A HFC pode contribuir para uma melhor compreensão de diversos aspectos relativos à natureza da ciência, como a falibilidade dos cientistas, a relação entre a ciência e a sociedade, a percepção da ciência como atividade humana. Atrelado a isso, a sua utilização pode propiciar um melhor aprendizado dos próprios conceitos científicos.

Este trabalho objetiva analisar um capítulo da história da óptica, enfatizando a aceitação da teoria corpuscular no século XVIII. Logo após evidenciaremos os seus aspectos pedagógicos.

Neste trabalho, em particular, pretende-se questionar a visão equivocada de ciência e a problematizar. Para tal, tomaremos como ponto de partida algumas indagações relacionadas a natureza da ciência, por exemplo: Qual a imagem feita do cientista? Ele é totalmente racional? As teorias físicas são frutos, puramente, advindos da razão do cientista? Será que fatores não-racionais ${ }^{2}$ fazem parte do fazer científico?

Pretendemos, com a análise desse episódio, oferecer elementos para os professores de Física elaborem atividades embasadas na HFC, melhorando as suas práticas em sala de aula.

\section{O ÓPTICA DE NEWTON}

O século XVII, principalmente, devido a Revolução Científica foi marcado pela mudança de idéias e ideais. Percebe-se que o ideal religioso centrado nos estudos teológicos foi pouco a pouco mudado pelo pensamento matematizado e pela experimentação. Neste

\footnotetext{
${ }^{1}$ Entende-se por natureza da ciência $(\mathrm{NdC})$, o conjunto de conhecimentos sobre a ciência que trata de seus limites, influências com a sociedade da época, os seus objetivos entre outros.

${ }^{2}$ Para o autor, fatores de natureza purarmente racionais são os atrelados a fundamentação teorica de uma teoria.
} 
período, a idéia de popularizar a ciência ganha espaço no cenário científico e social (SILVA; MARTINS, 2008).

É nesse cenário que Newton publicaria os seus trabalhos sobre a óptica. Nos anos de 1670 e 1672, Newton foi nomeado professor lucasiano de matemática da Universidade de Cambridge. Ele resolve, com apenas 27 anos, fazer aulas inaugurais sobre a teoria das cores e da refração. Esta exposição seria a mais abrangente sobre óptica feita por Newton, servindo como base para o livro I do Óptica ${ }^{3}$ duas décadas depois (COHEN; WESTFALL, 2002).

Já nos primeiros anos de seus estudos acadêmicos Newton se preocuparia em estudar assuntos relacionados a mecânica ${ }^{4}$, a óptica, a matemática e, também, a teologia. Mas, é sobre a óptica que Newton teria a sua primeira paixão e, também, a sua grande primeira decepção, que viria atrelada a críticas a alguns dos seus trabalhos, os quais, implicitamente, defendiam idéias de natureza corpuscular da luz.

Um dos principais debatedores de Newton foi Robert Hooke (1635-1703). No seu livro Micrographia, em 1672, afirma que:

A luz é produzida por vibrações de um meio sutil e homogêneo e este movimento se propaga por impulso ou ondas simples e de forma perpendicular à linha de propagação (HOOKE apud ROCHA, 2002, p.230).

Já Christiaan Huygens (1629-1695) com a publicação, em 1678, do livro "Tratado sobre a luz" se posiciona contra o modelo corpuscular, como verificamos na passagem a seguir:

[...] quando vemos um objeto luminoso, isso não poderia ocorrer pelo transporte de uma matéria que venha do objeto até nós, como uma flecha ou bala que atravessa o ar (HUYGENS, 1986, p.12).

Entretanto, Newton não defendeu abertamente a corporeidade da luz (SILVA; MOURA, 2008), como podemos vê nas suas próprias palavras:

É verdade que, a partir de minha teoria, argumento pela corporeidade da luz; contudo, faço isto sem qualquer certeza, como a palavra talvez deixa implícito; e o faço, no máximo, como uma conseqüência muito plausível da doutrina, não como uma suposição fundamental (ROTHMAN, p.37, 2005).

As constantes críticas ao seu trabalho fizeram que surgisse em Newton um grande descontentamento em continuar suas pesquisas na ciência óptica. Isto levou ao adiamento da publicação do Óptica, que só seria publicado em primeira edição em 1704, logo após a morte de Hooke.

\footnotetext{
${ }^{3}$ O Óptica de Newton publicado em 1704 contém três livros, onde ele discute fenômenos ópticos como reflexão, refração, a sua teoria sobre as cores entre outros. Destacaremos na sua obra as famosas questões, onde ele expões em forma de perguntas as suas principais idéias sobra a natureza corpuscular da luz.

${ }^{4}$ Sobre a mecânica, destacaremos a sua obra mais famosa, mais conhecida por Principia, publicada pela primeira vez em 1687.
} 
Entretanto, esta obra foi de grande influência para os estudos da óptica desenvolvida no início do século XVIII na Inglaterra, pois diferente do "Principia", possuidor de uma linguagem matemática extremamente complexa, o Óptica era baseado em discussões de experimentos e proposições, o que o tornava uma leitura mais agradável para os leitores da época.

\section{A ACEITAÇÃO AO ÓPTICA DE NEWTON}

A ciência daquela tempo tinha no empirismo um pilar muito significativo, onde os pensadores acreditavam, com convicção, que deveria ser por meio da experimentação e da matematização do fenômeno o caminho a se seguir. Surge, por consequência, o uso indiscriminado do termo filosofia experimental (SILVA; MARTINS, 2008).

Nas primeiras linhas do livro I, diz Newton, com propriedade, o seu objetivo naquela obra:

Meu objeto neste livro não é explicar as propriedades da luz por hipóteses, mas propô-las e prová-las pelo raciocínio e por experiências (NEWTON, p.39, 2002).

Nas palavras de Newton percebemos o seu lado empirista ${ }^{5}$ e um reforço ao indutivismo, marco da filosofia experimental, que foi destaque naquele período da história da física, e encontrará em Newton um dos seus maiores desenvolvedores.

$\mathrm{Na}$ sua obra "Óptica", Newton traz várias questões onde ele apresenta argumentos em relação a natureza da luz e ,em especial, sobre sua materialidade. Por exemplo, na questão 29, em especial, Newton apresenta o caráter corpuscular da luz: "Os raios de luz não são corpos minúsculos emitidos pelas substâncias que brilham?" (NEWTON, 2002, p.271).

No seu livro - Óptica - Newton traz uma série de descrições muito bem elaboradas de uma gama de experimentos realizados por ele para demonstrar as propriedades da luz, como por exemplo: a reflexão, refração, a inflexão da luz, e, também, sobre as cores.

Os seus seguidores consideravam suas idéias encontradas, principalmente, no Óptica seriam encaradas como verdades absolutas e de fácil verificação. Como podemos ver em John Harris (1666-1719):

[...] os raios de luz são certamente pequenas partículas, realmente emitidas do corpo luminoso e refratados por alguma atração, pela qual a luz e o corpo sobre o qual ela cai agem mutuamente um no outro, pois tais partículas ou corpúsculos serão transmitidos através de meios uniformes em linha reta, sem qualquer inflexão, como os raios de luz fazem (HARRIS, 1723, apud Moura; Silva, 2007, p.5).

\footnotetext{
${ }^{5}$ Mesmo que Newton tente reforçar nas suas palavras uma aversão a possibilidade de se fazer hipoteses, principalmente do livro II do Óptica, e em vários outros trechos podemos perceber a existência de hipoteses realizadas por Newton.
} 
A mesma crença na obra de Newton é percebida em Robert Smith (1689-1789) que, também, acreditava na natureza corpuscular da luz. Na sua obra "A compleat system of optics" publicado em 1738, ele diz:

[...]suas partículas serão aceleradas ou retardadas na mesma direção perpendicular, conforme o poder do meio agir a favor ou contra o curso de seus movimentos; e quando as partículas saem daquele espaço, elas proseguirão com uma velocidade uniforme (SMITH, p.21, 1778 apud MOURA; SILVA, p.6, 2007).

Distante de tudo isso, importantes teorias do Óptica ,como os anéis de Newton, não foram levados muito em conta pelos seus adeptos, pois o interesse da época residia em formar um corpo conceitual coeso entre a materialidade da luz e sua interação com os corpos (SILVA; MOURA, 2008; SILVA; MARTINS, 2008).

Isto levaria a uma total escassez de estudos em pontos críticos da teoria newtoniana (massa e volume das partículas, o conceito de força dos corpos para refletir e refratar, o conceito de inflexão, a influência da gravitação, entre outros) que não apresentavam um melhor arcabouço conceitual. A maior preocupação dos cientistas daquela época era, realmente, a idealização de modelos dinâmicos para a luz. E, muito nos parece que a materialidade para a luz era fato consumado e acreditado por todos os seguidores de Newton.

Contudo, a falta de estudos sobre pontos críticos do Óptica abriria espaços para a teoria ondulatória, que por sua vez tentaria explicar pontos obscuros da obra newtoniana, avançado os estudos sobre a luz ${ }^{6}$ no século XVIII.

\section{A AUTORIDADE NEWTONIANA}

A maior crença no Óptica de Newton foi fruto do sucesso de outra obra sua: o "Principia", onde se estabelece as leis de Newton para a mecânica. Nesta obra ele ,também, retrata a óptica em algumas proposições.Os seguidores de Newton acreditavam nos preceitos contidos no Óptica como verdades absolutas e não se preocuparam em desenvolver pontos críticos da obra newtoniana como, por exemplo: massa e volume das partículas, o conceito de força dos corpos para refletir e refratar, o conceito de inflexão, a influência da gravitação, entre outros. Estes pontos críticos serviram de partida para o surgimento da teoria ondulatória na segunda metade do século XVIII.

Entretanto, a teoria corpuscular muito se benificiava da "divulgação científica" gerada ao redor de Newton e de suas idéias...

No século XVIII nas aulas populares ${ }^{7}$ era evidenciado os pontos críticos da teoria ondulatória e reforçada a teoria corpuscular. E, ainda, muito dos experimentos que

\footnotetext{
${ }^{6}$ Vale salientar que somente na segunda metade do século XVIII surgiria propriedades típicas de onda (amplitude, comprimento de onda, frequência) no estudo sobre a luz. É muito comum os livros didáticos atribuirem a Hooke e Huygens características ondulatórias. Tais características viriam a ser discutidas somente no século XVIII.
} 
divergiam das explicações de Newton foram desconsiderados ,pois, seus intrumentos deveriam ser defeituosos (COHEN; WESTFALL, 2002). Parece-nos que todos os fatos colaboravam para uma maior aceitação das concepções newtonianas.

Será que a imagem e a autoridade newtoniana colaborou para que a teoria corpuscular fosse privilegiada no século XVIII?

Ainda no fim do século XVII e início do século XVIII, as universidades eram compostas por professores escolásticos e cartesianos. Logo, a visão vibracional para a luz tinha adeptos, visto que, os escolásticos baseados em Aristóteles - idealizador ,na Antiguidade, de um modelo para a luz de natureza vibracional -, seguiam os preceitos do tutor da Grécia.

Vivíamos um período de profundas mudanças, onde Newton o marcou fortemente. A primeira edição dos Principia foi dedicado ao seu patrono, o rei James II. Neste mesmo período, Newton foi eleito presidente da Royal Society. Já por sua influência, ocorreu uma substituição, nas principais universidades, de professores escolásticos e cartesianos por newtonianos ortodoxos (PEDUZZI, 2006).

Entretanto, os adeptos de uma materialidade para a luz deixavam de lado alguns problemas encontrados na visão newtonina, por exemplo: massa e volume das partículas, o conceito de força dos corpos para refletir e refratar, o conceito de inflexão, a influência da gravitação, entre outros.

Já nas conferências não eram discutidos fenômenos que não pudessem ser contemplados pela teoria dinâmica da luz, como a teoria dos estados de fácil transmissão e fácil reflexão ${ }^{8}$.

Os pontos críticos da teoria corpuscular juntamente com a falta de estudos que pudessem sanar tais dificuldades, possibilitou aos adeptos da teoria ondulatória o ressurgimento de estudos nesta linha de pesquisa.

Atrelado a isto, em especial, na segunda metade do século XVIII inicia-se uma busca em explicar a luz tomando como base teorias ondulatórias. Entretanto, a influência e a autoridade newtoniana dificultou o desenvolvimento de trabalhos nesta linha de raciocínio.

Portanto, conclui-se que a visão newtoniana apresentava dificuldades na explicação de alguns fenômenos. E, devido a sua autoridade outros estudos sofreram barreiras para a sua plena concretização. Além disso, a sua grande influência, com destaque na Inglaterra, seria de suma importância para que suas idéias continuassem como incontestáveis em boa parte do século XVIII.

\section{CONTRIBUIÇÕES AO ENSINO}

A literatura especializada (VANNUCCHI, 1996; GARCÍA et al., 2007; IPARRAGUIRRE, 2007) relata que a forma pela qual a Física, e, em especial, a Óptica é repassada aos alunos não garante o aprendizado de teorias físicas.

\footnotetext{
${ }^{7}$ Com a revolução científica, na Inglaterra, em especial, ocorreu uma tentativa de popularizar a ciência. Naquele tempo, os cientistas realizavam, em praça pública, experimentos e ministravam aulas para o público menos escolarizado.

${ }^{8}$ Para maiores esclarecimentos vê: MOURA; SILVA, 2007; SILVA; MARTINS, 2008; SILVA; MOURA, 2008.
} 
Para Iparranguirre (2007) e García et al.,(2007) os alunos após o ensino de teorias físicas apresentam dúvidas em relação a leis básicas da Física. A forma como estes contéudos são repassados muitas vezes tornam-se sem significados para os aprendizes.

Espera-se que com a inserção da HFC nas salas de aulas e, também, a inserção nos currículos de discussões sobre a natureza do conhecimento científico, mudanças como estas possam vir a melhorar as aulas de ciências e, por consequência, logrem melhores resultados.

Martins (2007) nos aponta que, ainda, hoje, existem muitas dificuldades de inserção de elementos de história e de filosofia da ciência no ensino. Isto deve-se, em muitos casos: devido a falta de material, pela dificuldade de trabalhar leituras com os alunos e, principalmente, pela rigidez dos currículos escolares.

Entretanto, a inserção da HFC no ensino, hoje, é encarado como de fundamental importância para a melhoria do ensino de ciência (ver p.ex: MATTHEWS, 1995; VANNUCCHI, 1996; MARTINS, 2007).

E, ainda, o conhecimento por parte dos professores de episódios históricos ajudará como propulsor para discussões sobre a natureza da ciência no ensino de ciências, e, em particular, o de Física.

Castro (1993) apud Nascimento (2006) nos alerta que

Quando o aluno discute de onde veio tal idéia, como ela evoluiu até chegar onde está, ou mesmo questiona os caminhos que geraram esta evolução, de certa forma, ele nos dá indícios de que reconhece tais conceitos como objeto de construção e não como conhecimentos revelados ou meramente passíveis de transmissão. Buscar razões, pois, parece indiciar um comprometimento maior com o que se estuda e se, além disso, o aluno argumenta, baseando-se em informações históricas (busca o respaldo para o que diz na fala das "autoridades") além de estar usando a analogia, ferramenta extremamente útil no estudo das ciências, ele está se reconhecendo também como sujeito construtor de saber.

Mas, o que podemos aprender em particular, com o episódio histórico apresentado aqui?

Como vimos durante quase todo século XVIII, as teorias para a luz baseadas nas idéias corpusculares de Newton tiveram um maior destaque em relação as teorias de cunho ondulatório.

O que se deve indagar é: será que a supremacia de teorias baseadas nas idéias newtonianas, ou a própria teoria de Newton foram plenamente aceitas devido a sua melhor fundamentação teorica e racional? Será que fatores não racionais influenciaram para uma melhor aceitação das idéias newtonianas? A teoria corpuscular viveu sem indagações durante este período? 


\section{A INSERÇÃO DE FATORES NÃO-RACIONAIS}

Com a análise desse episódio da história da óptica esperamos evidenciar que durante a construção de teorias e leis científicas, fatores não racionais são de relevância para que idéias de um ou outro cientistas prevaleça. No caso, em especial, da controvérsia existente em relação a natureza da luz - onda ou partícula - podemos perceber que a crença nas teorias newtonianas e a sua autoridade foram de suma importância para a aceitação da teoria corpuscular da luz durante as primeiras décadas do século XVIII.

Neste caso, em especial, podemos perceber que a autoridade newtoniana adquirida com a publicação do Principia foi de relevância para a maior aceitação de sua visão corpuscular para a luz, e, por consequência, os fatos que se sucedem, logo após a eleição de Sir. Issac Newton como presidente da Royal Society, como, por exemplo, entre eles, a mudança de professores escolásticos e catersianos por newtonianos, levou a uma maior divulgação de suas idéias nas universidades da Inglaterra.

No turno da didática das ciências podemos destacar que leis e teorias são influenciadas por fatores não racionais; por exemplo, o posto de presidente da Royal Society, que possibilitaria a Newton delegar os assuntos científicos nos quais os pesquisadores deveriam se debruçar.

Neste episódio, outro ponto, que merece destaque é aceitação sem precendetes das teses elaboradas por Newton pelos seus seguidores, em destaque John Harris e Robert Smith os quais acreditavam cegamente nos preceitos newtonianos como acompanhamos no episódio comentado.

Então, será que a ciência avança sem contestações? Será que a teoria corpuscular não oferecia pontos os quais mereciam um estudo mais detalhado?

Podemos responder que sim. A teoria newtoniana apresentava vários pontos não explicados ou a completar, estes, esquecidos ou ignorados pelos seguidores de Newton.

Isto muito se deu, primeiro, pela fé convicta na tese newtoniana. Segundo, pela sua autoridade e influência sobre os demais pesquisadores. E, por fim, a idealização, daquela época de criar um modelo dinâmico para a luz, que muito impediu o desenvolvimento de outras teorias.

\section{CONCLUSÃO}

Hoje com a rejeição para a educação científica, por parte dos alunos e até de jovens que desejem entrar nas carreiras científicas, acreditamos que a inserção da HFC possa vir a ser um elemento diferencial para o despertar científico, a muito adormecido no imaginário dos nossos estudantes do ensino médio.

No papel de professores, tentamos inserir conteúdos de HFC no ensino de Ciências. Este estudo analisado serve de base para criação de materiais com tais características para o seu uso no ensino médio. Já os seus resultados desta experiência servirão como objeto de construção de outros trabalhos. 


\section{REFERÊNCIAS}

BRASIL. MINISTÉRIO DA EDUCAÇÃO E CULTURA. Parâmetros Curriculares Nacionais - Ensino Médio. Brasília: 2002.

CAMPANARIO, Juan Miguel. Ventajas e incovenientes de la historia de la ciencia como recurso de la enseñanza de las ciencias. Revista de Enseñanza de la Física. v.11, p.5-14, 1998.

CASTRO, Ruth Schimtz. Uma e outras histórias. In: Ensino de ciências: unindo a pesquisa e a prática. CARVALHO, Anna Maria (org). São Paulo: Pioneira Thomson Learning, 2006.

COHEN, I. Bernard; WESTFALL, Richard S.. Newton: Textos-AntecedentesComentários. Rio de Janeiro: Eduerj, 2002.

GARCÍA, Luís Osuna et al. Planificando la enseñanza problematizada: el ejemplo de la óptica geométrica em educación secundaria. Enseñanza De Las Ciencias, Madrid, v. 2, n. 25, p.277-294, 2007.

IPARRAGUIRRE, Lorenzo Marcos. Uma propuesta de utlización de la historia de la ciencia em la enseñanza de um tema de Física. Enseñanza de las ciencias. v.25, n.3, p423-434, 2007.

MARTINS, André Ferrer Pinto. História e Filosofia da Ciência no ensino: há muitas pedras nesse caminho... Caderno Brasileiro de Ensino de Física, Florianópolis, v. 24, n. 1, p.112-131, 2007.

MATTHEWS, Michael R. História, Filosofia e Ensino de Ciências: a tendência atual de reaproximação. Caderno Catarinense de Ensino de Física, Florianópolis, v. 12, n. 3, p.164-214, 1995.

MOURA, Breno Arsioli; SILVA, Cibelle Celestino. A Óptica Newtoniana no Século XVIII: o que podemos aprender com esse episódio. Anais do Enpec, São Paulo, p.1-11, 2007.

NEWTON, I. Óptica. Tradução: ASSIS, André Koch Torres. São Paulo: EDUSP, 2002.

PEDUZZI, Luiz. O. Q. Sobre continuidades e descontinuidades no conhecimento científico: uma discussão centrada na perspectiva Kunhiana. In: Estudos de História e Filosofia das ciências. São Paulo: Livraria da Física, 2006.

ROCHA, José Fernando Moura. Origem e Evolução do Eletromagnetismo. In: ROCHA, José Fernando Moura (org). Origens e Evolução das Idéias da Física. Salvador: EDUFBA, 2002.

ROTHMAN, Tony. Tudo é relativo: e outras fábulas da ciência e tecnologia. Rio de Janeiro: Editora Difel, 2005. 
SILVA, Fábio W.O. A Evolução da teoria ondulatória da luz e os livros didáticos. Revista Brasileira de Ensino de Física, São Paulo, v. 29, n.1, p. 149-159, 2007.

SILVA, Boniek Venceslau da Cruz; MARTINS, André Ferrer Pinto. A experiência de Young: a pedra da roseta da natureza da luz? Anais do XI EPEF, Curitiba, p.1-12, 2008.

SILVA, Cibelle Celestino; MOURA, Breno Arsioli. A natureza da ciência por meio do estudo de episódio históricos: o caso da popularização da óptica newtoniana. Revista Brasileira de Ensino de Física, São Paulo, v.30, n.1, 2008.

SOLBES, J; TRAVER, M.J. La utililización de la historia de las ciencias em la enseñanza de la física y de la química. Enseñanza de las Ciencias. v.14, p.103-112, 1996.

VANNUCCHI, Andréa Infantosi. História e Filosofia da Ciência: da teoria para a sala de aula. 1996. Dissertação de Mestrado apresentada ao Instituto de Física e à Faculdade de Educação da USP, Universidade de São Paulo, São Paulo. 